Check for updates

Cite this: RSC Adv., 2018, 8, 7942

Received 23rd December 2017 Accepted 7th February 2018

DOI: $10.1039 / c 7 r a 13614 \mathrm{e}$

rsc.li/rsc-advances

\section{High sensitivity glucose detection at extremely low concentrations using a $\mathrm{MoS}_{2}$-based field-effect transistor}

\begin{abstract}
Junjie Shan, ${ }^{a}$ Jinhua Li, (D) ${ }^{* a}$ Xueying $\mathrm{Chu},{ }^{a}$ Mingze $\mathrm{Xu},{ }^{a}$ Fangjun Jin, ${ }^{a}$ Xiaojun Wang, Li Ma, ${ }^{\text {b }}$ Xuan Fang, ${ }^{\text {ac }}$ Zhipeng Weic and Xiaohua Wang ${ }^{\mathrm{c}}$

In recent years, molybdenum disulfide $\left(\mathrm{MoS}_{2}\right.$ ) based field-effect transistors (FETs) have attracted much attention because of the unique properties of $\mathrm{MOS}_{2}$ nano-materials as an ideal channel material. Using a MoS 2 FET as a glucose solution biosensor has the advantages of high sensitivity and rapid response. This paper is concerned with the fabrication of a bilayer $\mathrm{MOS}_{2}$-based FET and the study of its application in the high sensitivity detection of an extremely low concentration glucose solution. It was found that the source-drain current $\left(I_{\mathrm{ds}}\right)$ increases as the concentration of the glucose solution increases at the same gate voltage $\left(V_{\mathrm{gs}}\right)$ and drain voltage $\left(V_{\mathrm{ds}}\right)$. The sensitivity of the biosensor as high as $260.75 \mathrm{~mA} \mathrm{mM}^{-1}$ has been calculated and the detection limit of $300 \mathrm{nM}$ was measured. The unknown concentration of a glucose solution was also detected using data based on the relationship between $I_{\mathrm{ds}}$ and glucose solution concentration. In addition, many significant advantages of the biosensor were observed, such as short response time ( $<1 \mathrm{~s})$, good stability, wide linear detection range $(300 \mathrm{nM}$ to $30 \mathrm{mM})$ and the micro-detection of glucose solutions. These unique properties make the bilayer $\mathrm{MOS}_{2}$-based FET a great potential candidate for next generation biosensors.
\end{abstract}

\section{Introduction}

FETs are an important part of modern microelectronic technology for the advantages of high input resistance, low noise, low power consumption, large dynamic range, easy integration, non secondary breakdown phenomenon and wide safe working range. The main applications of FETs are in amplified circuits, impedance conversion, variable resistance, constant current sources, electronic switches and so on. $\mathrm{MoS}_{2}$ is an ideal channel material for FETs due to the small number of dangling bonds on the surface of $\mathrm{MoS}_{2}$ and its stable structure. ${ }^{1-8}$ FETs based on $\mathrm{MoS}_{2}$ have the advantages of high switching current ratio, high carrier mobility and low energy dissipation, which meet the requirements of smaller size, lower cost, less power consumption, and faster computing in integrated circuits for modern electronic products. ${ }^{7,8}$ Applications of $\mathrm{MoS}_{2}$ FETs in novel electronic devices such as electrochemical sensors, biosensors, solar cells, and gas sensors, have recently been reported., ${ }^{\mathbf{9} 10}$

In recent years, the sensors based on $\mathrm{MoS}_{2}$ FETs have been developed to detect various species such as $\mathrm{H}_{2} \mathrm{O}_{2}, \mathrm{NO}_{2}, \mathrm{NH}_{3}$,

${ }^{a}$ School of Science, International Joint Research Center for Nanophotonics and Biophotonics, Changchun University of Science and Technology, 7089 Wei-Xing Road, Changchun 130022, P. R. China. E-mail: jhli_cust@163.com; Tel: +860431 85582739

${ }^{b}$ Department of Physics, Georgia Southern University, Statesboro, GA 30460, USA

${ }^{c}$ State Key Laboratory of High Power Semiconductor Laser, Changchun University of Science and Technology, 7186 Wei-Xing Road, Changchun 130028, P. R. China
DNA, proteins and so on. These devices have attracted huge interest because of the advantages such as high sensitivity, low detection limit, label free detection, low power consumption, portability and large scale production. ${ }^{9,11-17}$ The sensor and the test system can also be integrated on a chip to actualize the macroscopic and fast detection of the measuring object.9,18 Relevant research shows that the sensitivity of a $\mathrm{MoS}_{2}$-based pH sensor has been achieved as high as $59 \mathrm{mV}$ per $\mathrm{pH}$. Ultrasensitive and specific protein sensing has also been achieved with a sensitivity of $196 \mathrm{mV}$ per $\mathrm{pH}$ even at 100 femtomolar concentration. ${ }^{11}$ Zhou and his group have demonstrated the good sensing performance of the $\mathrm{MoS}_{2}$ FET towards nitrogen dioxide $\left(\mathrm{NO}_{2}\right)$ and ammonia $\left(\mathrm{NH}_{3}\right)^{.9}{ }^{, 19}$

Some of the salient features of $2 \mathrm{D}$ layered $\mathrm{MoS}_{2}$ for different sensing applications have been researched, including the biosensing, gas sensing, electrochemical sensing and SERS sensing. ${ }^{9}$ Due to the wide application of sensitive and reliable glucose sensing in clinical diagnosis, food analysis and biotechnology, the development of glucose sensor has received continuous interest. ${ }^{20}$ The detection of glucose in blood and cells will be significant for medical study. ${ }^{21}$ Currently, the electrochemistry method is mainly used for the detection of glucose concentration. ${ }^{22-25}$ But this method requires the environment containing a large amount of liquid, which leads the activity of biological protein molecules to be affected seriously by temperature, toxicity and $\mathrm{pH}$ value of the environmental. The microdetection of glucose solution cannot be achieved accurately and the detection process is cumbersome and lacks stability. 
At recent reports, FET based glucose biosensor have been successfully prepared by different channel materials, such as carbon nanotubes, $\mathrm{ZnO}$ and graphene. The biosensor based on graphene FET has a narrow linear range $(3.3-10.9 \mathrm{mM}) .{ }^{26}$ The linear range can be broadened to a large extent when the channel material is replaced by carbon nanotubes or $\mathrm{ZnO}^{27,28}$ But their long response time of $\sim 10 \mathrm{~s}$ is not conducive to the rapid and accurate concentration detection of glucose solution. On the other hand, researchers have corroborated through theoretical and experimental studies that the zero band gap of graphene limits its application in semiconductor devices. ${ }^{11}$ Contrast to graphene, the $\mathrm{MoS}_{2}$ which has the similar layered structure to graphene shows better promising properties for biosensors due to its non-zero band gap.,.$^{3,99-34}$ The layered $\mathrm{MoS}_{2}$ nanomaterial have been recently developed and employed in various applications, including some new sensors because of it layer-dependent electrical properties. ${ }^{9}$ In previous studies, $\mathrm{Li}$ et al. reported the observation of thickness reduction induced crossover of electrical contact at $\mathrm{Au} / \mathrm{MoS}_{2}$ interfaces. $^{35}$ They found that the interfacial potential barrier can be finely tailored from 0.3 to $0.6 \mathrm{eV}$ by merely varying the thickness of $\mathrm{MoS}_{2}$. The contact resistivity of devices slightly decreases with the reducing of $\mathrm{MoS}_{2}$ thickness, which mainly governed by the quantum confinement effect. ${ }^{35}$ In addition, the density of states of bilayer $\mathrm{MoS}_{2}$ nanosheet is three times higher than that of monolayer $\mathrm{MoS}_{2}$, leading to considerably high drive currents in the ballistic limit. The conducting channels can be created by field effect in bilayer $\mathrm{MoS}_{2}$ for boosting the current drive of FETs. ${ }^{36}$ Moreover, the Hall mobilities increase as the density of states increases, reaching $375 \mathrm{~cm}^{2} \mathrm{~V}^{-1} \mathrm{~s}^{-1}$ for the bilayer, in contrast to $250 \mathrm{~cm}^{2} \mathrm{~V}^{-1} \mathrm{~s}^{-1}$ for the monolayer. ${ }^{37}$ Therefore, the bilayer $\mathrm{MoS}_{2}$ FET based biosensor would exhibits the stable and high sensitive responses due to the strong impact of its structure and electrical properties. ${ }^{38}$ Unfortunately, the detection of glucose solution based on the $\mathrm{MoS}_{2}$ FET has not been reported so far. In our research, a biosensor based on the bilayer $\mathrm{MoS}_{2}$ back-gate FET was fabricated successfully and the application of the biosensor in detection of glucose concentration was demonstrated for the first time. We discovered that the $I_{\mathrm{ds}}$ of the biosensor increases with the increase of glucose concentration. Through the measurements of $I_{\mathrm{ds}}$, the $\mathrm{MoS}_{2}$ FET biosensor shown a good sensing performance. The high sensitivity of $260.75 \mathrm{~mA} \mathrm{mM}^{-1}$ and extremely low detection limit of $300 \mathrm{nM}$ have been achieved in our researches.

\section{Experimental section}

\section{Materials and reagents}

$\mathrm{MoS}_{2}$ bulk materials (Spi, SUPPLIES), D-glucose $\left(\mathrm{C}_{6} \mathrm{H}_{12} \mathrm{O}_{6} \cdot \mathrm{H}_{2} \mathrm{O}\right.$, 99.5\%), Glucose oxidase (GOx, from Aspergillus niger species, $\left.180 \mathrm{U} \mathrm{mg}^{-1}\right)$. Potassium phosphate monobasic $\left(\mathrm{KH}_{2} \mathrm{PO}_{4}, 99.5 \%\right)$, potassium phosphate dibasic trihydrate $\left(\mathrm{K}_{2} \mathrm{HPO}_{4} \cdot 3 \mathrm{H}_{2} \mathrm{O}, 99.0 \%\right)$, potassium hexacyanoferrate $\left(\mathrm{K}_{3}\left[\mathrm{Fe}(\mathrm{CN})_{6}\right]\right)$, potassium ferrocyanide $\left(\mathrm{K}_{4}\left[\mathrm{Fe}(\mathrm{CN})_{6}\right] \cdot 3 \mathrm{H}_{2} \mathrm{O}\right)$.
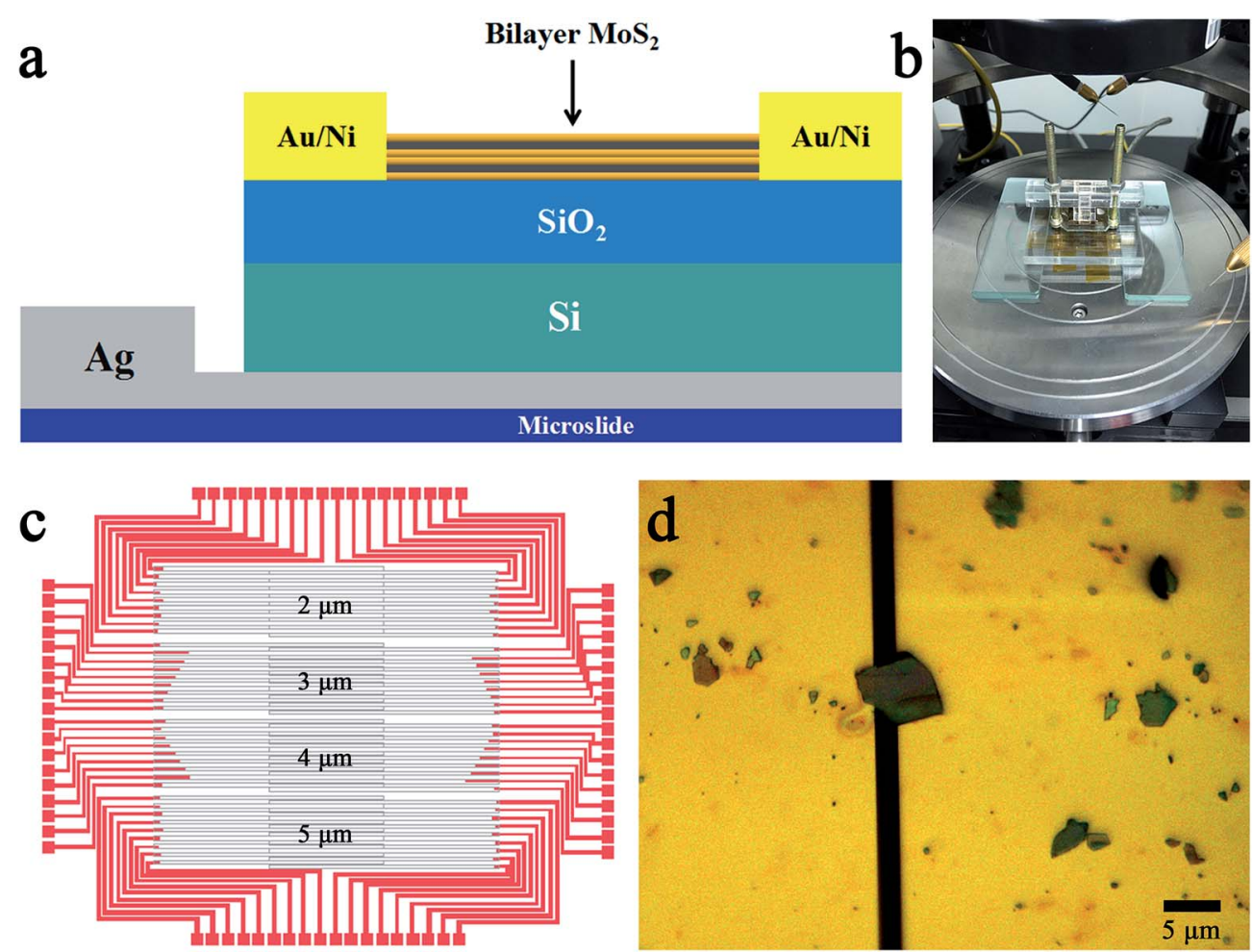

Fig. $1 \mathrm{MoS}_{2}$-based FET biosensor device. (a) Schematic diagram of the bilayer MoS 2 -based FET. (b) Optical image of the sample cell. The glucose solution is injected into the rectangular hole of the sample cell. (c) Image of the lithography board. Four kinds of devices with different channel widths, 2, 3, 4 and $5 \mu \mathrm{m}$, are included in the board. (d) The metallographic micrograph of the channel material stripped mechanically in the channel region of (c). The length and width of the $\mathrm{MoS}_{2}$ channel are 2 and $3 \mu \mathrm{m}$, respectively. 
The specific preparation process of the glucose solution with different concentrations is as follows: $80 \mathrm{~mL}$ of a $0.1 \mathrm{~mol} \mathrm{~L}^{-1}$ PBS solution was prepared as the solvent for the glucose solution, the PBS is a mixture of $\mathrm{KH}_{2} \mathrm{PO}_{4}, \mathrm{~K}_{2} \mathrm{HPO}_{4}, \mathrm{~K}_{3} \mathrm{Fe}(\mathrm{CN})_{6}$, and $\mathrm{K}_{4} \mathrm{Fe}(\mathrm{CN})_{6}$. The glucose of different quality was dissolved in PBS solution to guarantee the concentration of glucose solution as 0-30 mM. Appropriate amounts of glucose oxidase (GOx) was added to each glucose solution before testing.

\section{Fabrication of FET based glucose biosensors}

In our study, the different concentration of glucose solution was detected by a FET biosensor. The back-gate FET was adopted due to the surface of channel material had to contact with the glucose solution in the sensing process. The structure of the $\mathrm{MoS}_{2}$ FET is shown in Fig. 1a. In addition to the FET, a sample cell was also necessary. The sample cell which made of plexiglass was designed to three parts and screwed together with the $\mathrm{MoS}_{2}$ FET. The physical diagram of the sample cell is shown in Fig. 1b. In the process of testing, the glucose solution with different concentration was injected into the rectangular hole which above the sample cell. In order to protect the channel material, electrodes of the back-gate FET was formed on the $\mathrm{SiO}_{2} / \mathrm{Si}$ substrate which before the $\mathrm{MoS}_{2}$ was exfoliated. The source and drain electrodes were made of $\mathrm{Au} / \mathrm{Ni}(70 \mathrm{~nm} / 10 \mathrm{~nm})$, and the back gate electrode was made of quick-dry silver paste. The device was placed on a square glass plate $(1.5 \mathrm{~cm} \times 1.5 \mathrm{~cm})$ and the back-gate electrode was leaded to the glass plate. The specific process is as follows:

The first process is to design the board of the UV photolithography which was used to prepare the source and drain electrodes of $\mathrm{MoS}_{2}$ FET, as shown in Fig. 1c. The overlapping areas of the gray electrode leads are the channel regions of the FET. The channel width of the $\mathrm{MoS}_{2}$ FET was designed to 2, 3, 4 and $5 \mu \mathrm{m}$, respectively. The preparation of the electrodes were carried out by the UV photolithography technique and the electron beam (e-beam) evaporation technique on the $\mathrm{SiO}_{2} / \mathrm{Si}$ substrate. The next procedure is to exfoliate the highly mirrored $\mathrm{MoS}_{2}$ bulk materials in channel regions, which was shown in Fig. 1c. Micromechanical exfoliation (Scotch-tape method) is the traditional and the simplest technique used for the preparation of atomically thin layered $2 \mathrm{D}$ nanomaterials with high quality and crystallinity. ${ }^{9}$ This technology is widely used in preparation of the channel materials of FETs. Metallographic micrograph of the channel material was shown in Fig. 1d, the yellow parts were the source and drain electrode leads formed by the e-beam deposition of $70 \mathrm{~nm} / 10 \mathrm{~nm} \mathrm{Au} / \mathrm{Ni}$, and the black regions between the lead wires were the channel regions. The length and width of the $\mathrm{MoS}_{2}$ channel material we prepared are 2 and $3 \mu \mathrm{m}$, respectively. Subsequent characterizations and tests are all performed on this device. The final step is the preparation of back-gate electrode. A quick-drying silver paste was dripped on the backside of the $\mathrm{SiO}_{2} / \mathrm{Si}$ substrate. Then the device was placed on a square microslide and the back-gate electrode of the FET was led to the surface of the microslide, as shown in Fig. 1a. The three electrodes of the FET are facing upwards for subsequent tests.

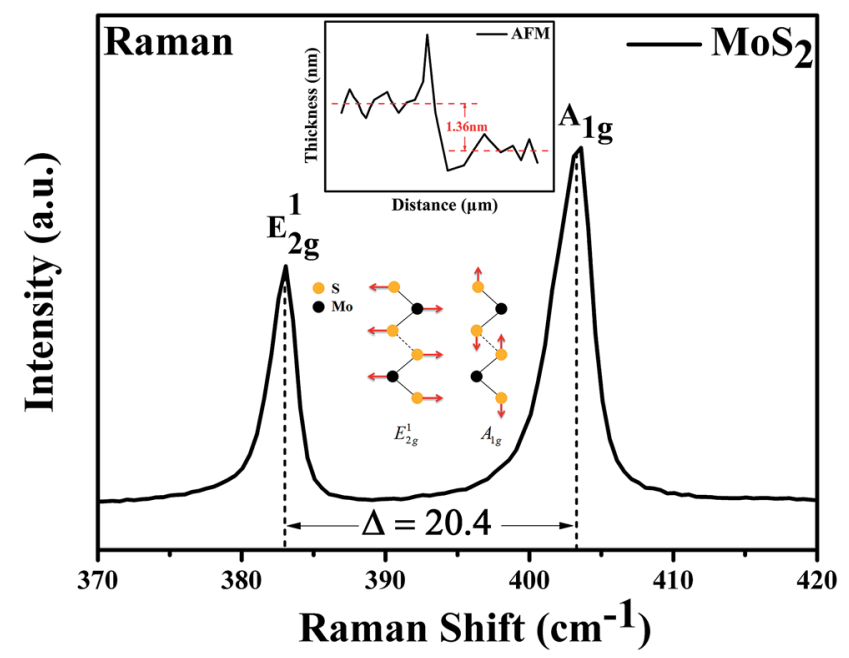

Fig. 2 Raman spectrum of the channel material. The number of layers of the $\mathrm{MoS}_{2}$ nanosheet we prepared can be confirmed as bilayer. Inset, the height gradient between the channel material and the underlying substrate was tested by the AFM, the thickness of the $\mathrm{MoS}_{2}$ channel material is $1.36 \mathrm{~nm}$.
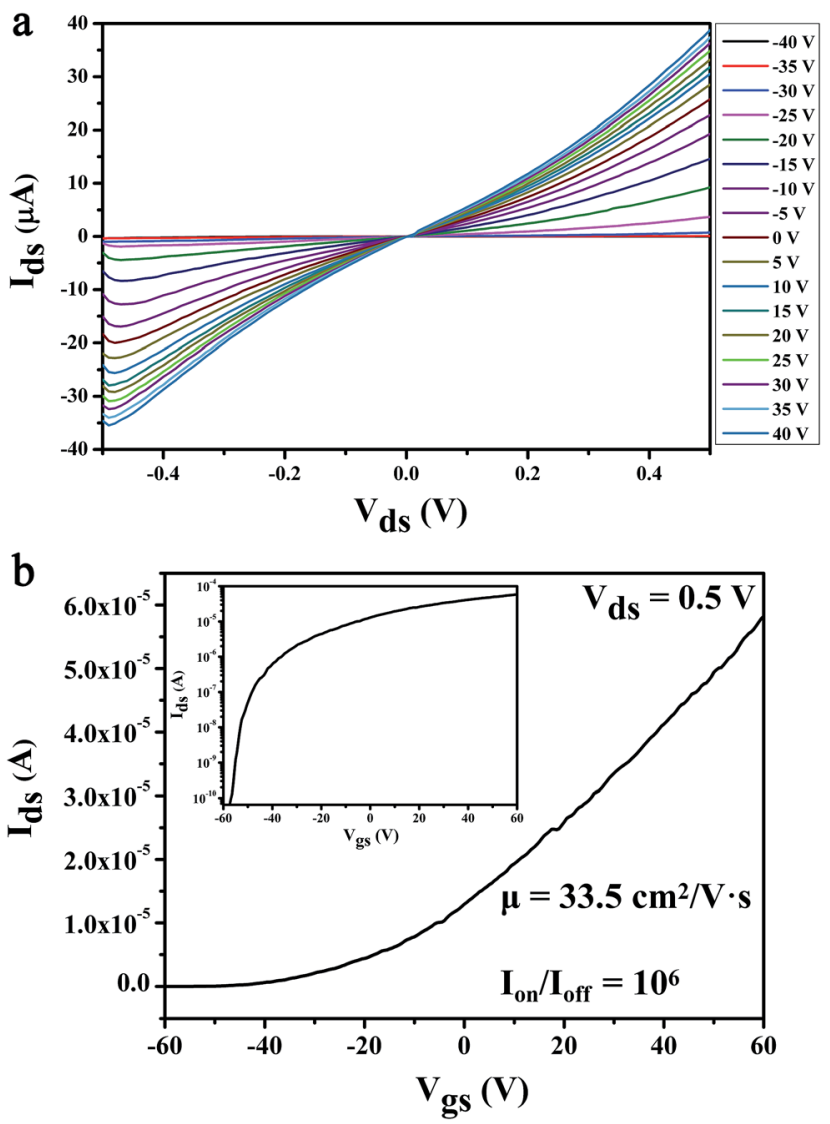

Fig. 3 The basic electrical characterization of the $\mathrm{MoS}_{2}$ FET. (a) Output characteristic curve of the device, drain current $\left(I_{\mathrm{ds}}\right)$ as a function of drain voltage $\left(V_{\text {ds }}\right)$ with the back gate voltage $\left(V_{\text {gs }}\right)$ varying from -40 to $40 \mathrm{~V}$, in a step of $5 \mathrm{~V}$. (b) Transfer characteristic curve of the device, $I_{\mathrm{ds}}$ as a function of $V_{\mathrm{gs}}$ with the $V_{\mathrm{ds}}$ of $0.5 \mathrm{~V}$. Inset, the logarithmic image of transfer characteristic curve $\left(I_{\mathrm{ds}}-V_{\mathrm{gs}}\right)$. 


\section{Measurements}

The thickness of the channel material $\left(\mathrm{MoS}_{2}\right.$ nanosheet) were tested by the atomic force microscope (AFM, Dimension 3100). And the number of layers of $\mathrm{MoS}_{2}$ also been determined by measuring the Raman spectra (labRAM HR E, HORIBA) according to the shift of the in-plane vibration mode $\mathrm{E}_{2 \mathrm{~g}}^{1}$ and the out-plane vibration mode $\mathrm{A}_{1 \mathrm{~g}}$. Then the basic electrical characteristics of the $\mathrm{MoS}_{2}$ FET without glucose solution were tested before the examination of sensing performance. A suitable device was selected as the glucose biosensor. At last, the changes of the electrical properties of biosensor with different glucose concentration were measured by the semiconductor parameter analyzer
(B1500, Keysight). The data of the relationship between the $I_{\mathrm{ds}}$ and the glucose concentration was obtained and the sensitivity of the glucose biosensor was calculated.

\section{Results and discussion}

\section{Basic characterization of $\mathrm{MoS}_{2}$ FET}

Characterization of the optical properties of the $\mathrm{MoS}_{2}$ by Raman spectroscopy is not only fast and accurate, but also does not destroy the crystal structure of the sample. The number of layers of the $\mathrm{MoS}_{2}$ can be determined by measuring the Raman shift of the in-plane vibration mode $\mathrm{E}_{2 \mathrm{~g}}^{1}$ and the out-plane vibration mode $\mathrm{A}_{1 \mathrm{~g}}$. For instance, the Raman shift of monolayer $\mathrm{MoS}_{2}$ is
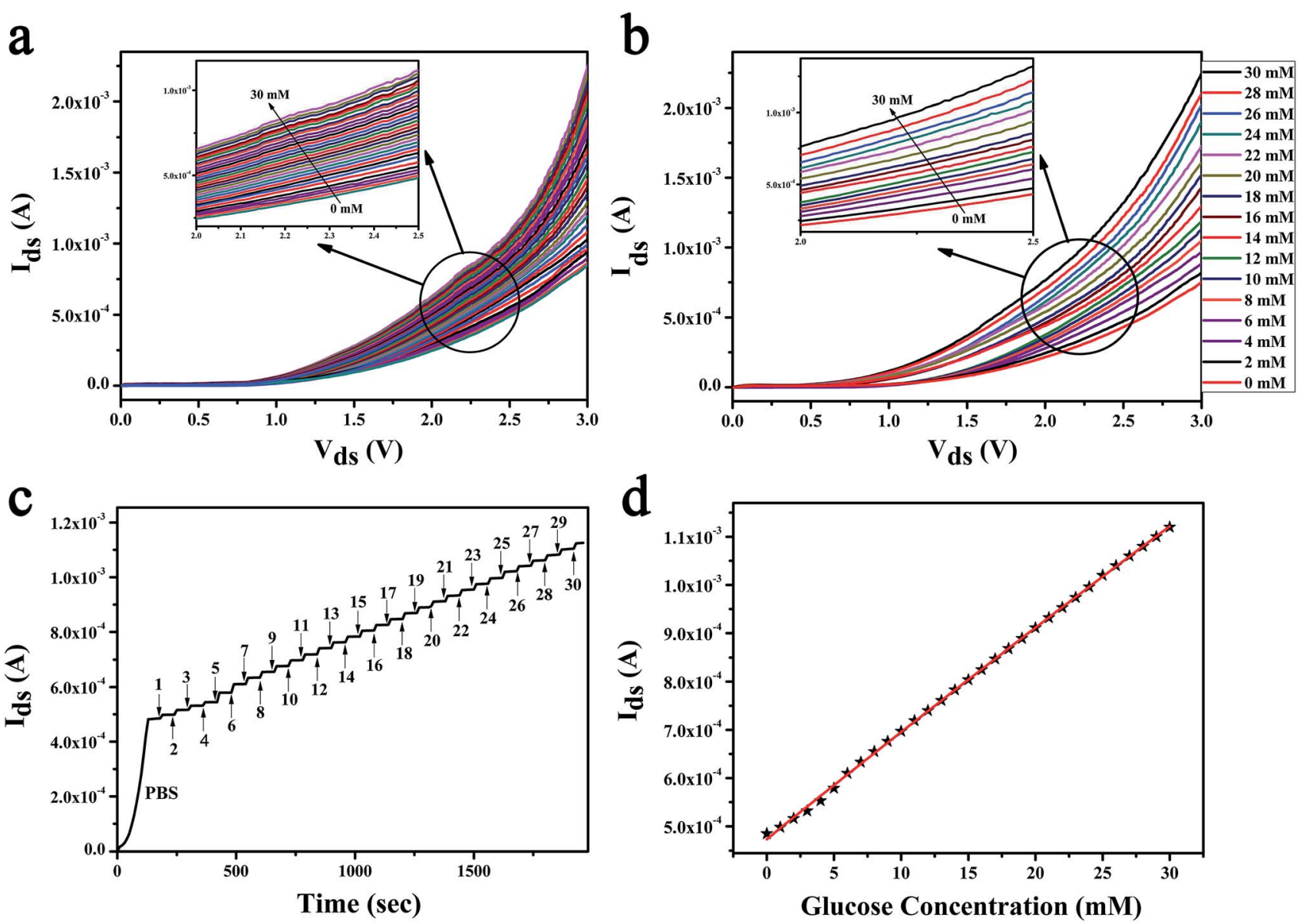

Fig. $4 \mathrm{MoS}_{2}$ FET sensor for glucose sensing. (a) Drain current for an n-type MoS 2 FET-based glucose sensor is plotted as a function of $V_{\text {ds }}$ for different concentrations of the glucose solution. (b) Repeatability experiments of the glucose sensing. The even number points of glucose concentration values are tested by the device used in the (a). (c) The real time current responses to the fluctuation of glucose concentrations. The glucose responses for the sequential concentration increase at $V_{\mathrm{gs}}$ of $0.5 \mathrm{~V}$ and $V_{\mathrm{ds}}$ of $2.5 \mathrm{~V}$. (d) The response curve of the MoS 2 FET to glucose solution. $I_{\mathrm{ds}}$ as a function of glucose concentration which is from 0 to $30 \mathrm{mM}$.

Table 1 The date of corresponding relationship between $I_{\text {ds }}$ and glucose concentration

\begin{tabular}{|c|c|c|c|c|c|c|c|c|c|c|}
\hline$I_{\mathrm{ds}}(\mathrm{mA})$ & 0.498 & 0.516 & 0.532 & 0.553 & 0.579 & 0.610 & 0.633 & 0.655 & 0.676 & 0.697 \\
\hline Glucose (mM) & 1 & 2 & 3 & 4 & 5 & 6 & 7 & 8 & 9 & 10 \\
\hline$I_{\mathrm{ds}}(\mathrm{mA})$ & 0.719 & 0.740 & 0.761 & 0.783 & 0.804 & 0.825 & 0.847 & 0.868 & 0.889 & 0.911 \\
\hline Glucose (mM) & 11 & 12 & 13 & 14 & 15 & 16 & 17 & 18 & 19 & 20 \\
\hline$I_{\mathrm{ds}}(\mathrm{mA})$ & 0.932 & 0.953 & 0.974 & 0.996 & 1.021 & 1.043 & 1.062 & 1.084 & 1.107 & 1.129 \\
\hline Glucose (mM) & 21 & 22 & 23 & 24 & 25 & 26 & 27 & 28 & 29 & 30 \\
\hline
\end{tabular}


16-18 $\mathrm{cm}^{-1}$; the Raman shift of bilayer and trilayer $\mathrm{MoS}_{2}$ are $21 \mathrm{~cm}^{-1}$ and $23 \mathrm{~cm}^{-1}$, respectively. ${ }^{39-43}$ The testing results of Raman spectroscopy shown that the Raman shift of $\mathrm{MoS}_{2}$ is $20.4 \mathrm{~cm}^{-1}$ with the excitation of the $532 \mathrm{~nm}$ laser, as shown in Fig. 2. It can be inferred that the channel material we prepared is the bilayer $\mathrm{MoS}_{2}$ nanosheet. In addition, the height gradient between the channel material and the underlying substrate was tested by the AFM, as shown in Fig. 2 inset. The test results shown that the thickness of the $\mathrm{MoS}_{2}$ channel material is $1.36 \mathrm{~nm}$, it also validated the Raman data of the bilayer $\mathrm{MoS}_{2}$ we have tested.

The electrical characteristics of the $\mathrm{MoS}_{2}$ FET have a strong impact on the sensitivity of the biosensor. The testing of the electrical properties of the $\mathrm{MoS}_{2}$ nanosheet based FET without glucose solution is shown in Fig. 3. As the output characteristic $\left(I_{\mathrm{ds}}-V_{\mathrm{ds}}\right)$ curve shown in Fig. 3a, the $I_{\mathrm{ds}}$ increases with the increase of $V_{\mathrm{ds}}$. Especially in the low voltage region of $V_{\mathrm{ds}}$, it can be observed that the $I_{\mathrm{ds}}$ increases linearly with $V_{\mathrm{ds}}$ and the curve pass through the original point, indicating that the good ohmic contact was formed between the electrodes and $\mathrm{MoS}_{2}$ layers, which is beneficial to the injection of electrons. The device can be effectively controlled by the $V_{\mathrm{gs}}$, which is illustrated by the output characteristic curve of the device with different $V_{\mathrm{gs}}$ in Fig. 3a; several important electrical parameters of $\mathrm{MoS}_{2}$ FET can be achieved from the transfer characteristic curve $\left(I_{\mathrm{ds}}-V_{\mathrm{gs}}\right)$ and the logarithmic image of $I_{\mathrm{ds}}-V_{\mathrm{gs}}$, which was shown in Fig. $3 \mathrm{~b}$ and its illustrations. According to calculation results: the fieldeffect mobility $(\mu)$ reached $33.5 \mathrm{~cm}^{2} \mathrm{~V}^{-1} \mathrm{~s}^{-1}$, the transconductance $\left(g_{\mathrm{m}}\right)$ was 1.7 and the switching current ratio $\left(I_{\text {on }} / I_{\text {off }}\right)$ was as high as $10^{6}$.

\section{Detection of glucose using $\mathrm{MoS}_{2}$ FET based biosensor}

In the research of glucose sensing performance, the output characteristic curves were tested with the different glucose concentration. Fig. 4a shown the $I_{\mathrm{ds}}$ of $\mathrm{MoS}_{2}$ FET varies with the concentration of glucose solution. This phenomenon can be explained by the enzymatic reaction of glucose with GOx and formation of the products. ${ }^{44}$ The underlaying sensing mechanism of the glucose biosensor based on bilayer $\mathrm{MoS}_{2}$ FET is attributed to the reaction of $\mathrm{H}_{2} \mathrm{O}_{2}$ generated by the oxidation of glucose. The details is that the glucose solution can generate gluconate and hydrogen peroxide $\left(\mathrm{H}_{2} \mathrm{O}_{2}\right)$ after being catalyzed by the glucose oxidase (GOx), and $\mathrm{H}_{2} \mathrm{O}_{2}$ will be dissociated and produce hydrogen ions $\left(\mathrm{H}^{+}\right)$and electrons $\left(\mathrm{e}^{-}\right)$. The concentration of electrons increases on the surface of conductive channel of the device with the process of enzymatic reaction. And the conductance of the channel material is increased because the $\mathrm{MoS}_{2}$ is a n-type semiconductor. This is due to the n-doping effect resulting from the direct electron transfer on the surface of the $\mathrm{MoS}_{2}$ nanosheet. There would be a charge transfer from the $\mathrm{H}_{2} \mathrm{O}_{2}$ molecules to the $\mathrm{MoS}_{2}$ channel. ${ }^{26,27,44-49}$ The glucose oxidation reaction is as follows:

D-Glucose $+\mathrm{H}_{2} \mathrm{O}+\mathrm{O}_{2} \stackrel{\text { GOx }}{\longrightarrow}$ D-gluconic acid $+\mathrm{H}_{2} \mathrm{O}_{2}$
$\mathrm{H}_{2} \mathrm{O}_{2} \rightarrow \mathrm{O}_{2}+2 \mathrm{H}^{+}+2 \mathrm{e}^{-}$
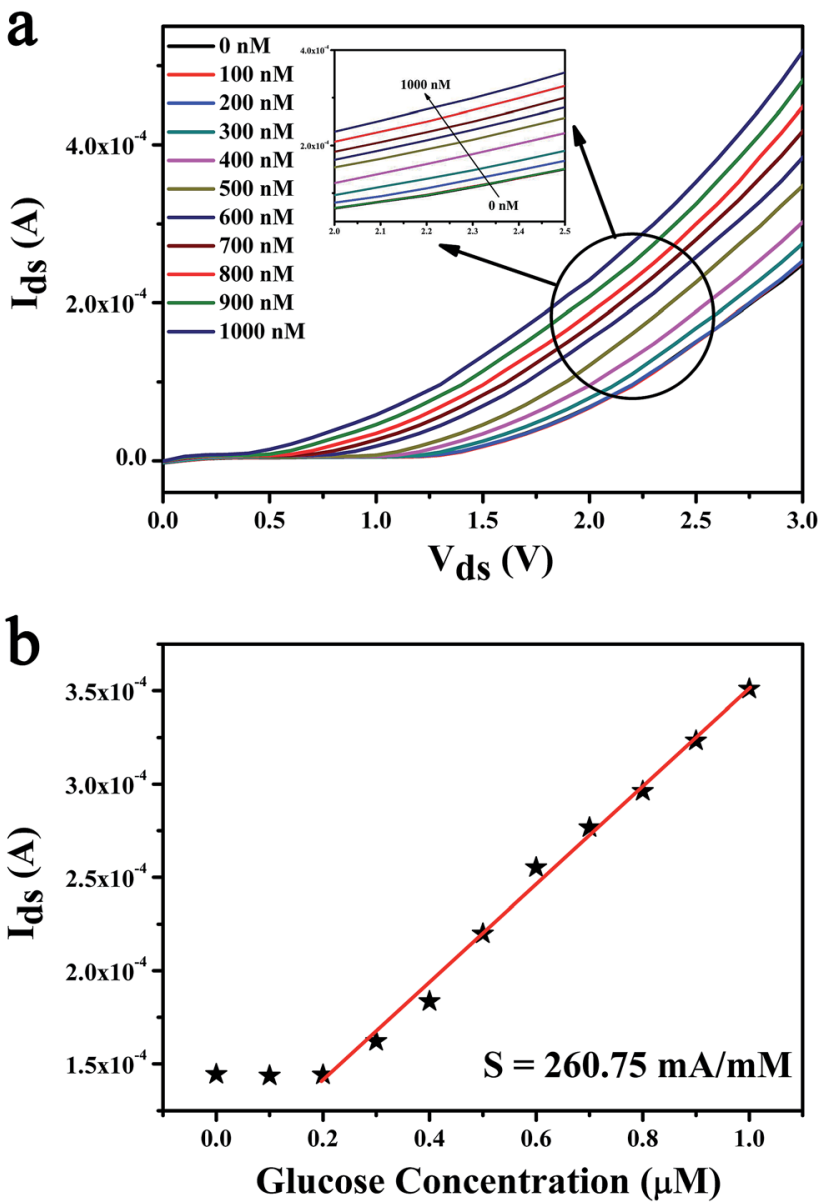

Fig. $5 \mathrm{MoS}_{2}$ FET sensor for ultra low concentration glucose sensing. (a) The detection limit of the biosensor based on $\mathrm{MOS}_{2}$ FET observed by the output characteristic curve is $300 \mathrm{nM}$. (b) Drain current as a function of glucose concentration which ranges from 0 to $1 \mu \mathrm{M}$ at $V_{\mathrm{gs}}$ of $0.5 \mathrm{~V}$ and $V_{\mathrm{ds}}$ of $2.5 \mathrm{~V}$. By calculation, the sensitivity of our biosensor has been achieved as high as $260.75 \mathrm{~mA} \mathrm{mM}^{-1}$.

The repeatability experiments were carried out by the same device and under the same conditions after 45 days. The device was used to test the even number points of glucose concentration values, as shown in Fig. 4b. The results shown that the device has a good stability. The real time sensor response to the addition of different concentration of glucose was shown in the Fig. 4c. The test was started with a pure PBS solution under fixed $V_{\mathrm{ds}}$ of $2.5 \mathrm{~V}$ and $V_{\mathrm{gs}}$ of $0.5 \mathrm{~V} .1 \mathrm{mM}$ glucose solution was first injected at $180 \mathrm{~s}$. And then, the glucose solution with higher concentrations were replaced the last one ever minute thereafter. The relationship between glucose concentration and the electrical parameters of $\mathrm{MoS}_{2}$ FET were shown in Fig. 4d. Then the unknown concentrations of glucose solution can be detected by the $I_{\mathrm{ds}}$ of the $\mathrm{MoS}_{2}$ FET $\left(V_{\mathrm{gs}}\right.$ of $0.5 \mathrm{~V}, V_{\mathrm{ds}}$ of $2.5 \mathrm{~V}$ ), as illustrated in Table 1.

\section{Sensitivity test}

In order to research the detection limit and the sensitivity of the $\mathrm{MoS}_{2}$ FET based biosensor, the glucose solution with extremely 
Table 2 Analytical features of some reported for glucose biosensors based on the $\mathrm{FET}^{a}$

\begin{tabular}{|c|c|c|c|c|c|}
\hline Modified surface & Sensitivity & LDR & DL & $\begin{array}{l}\text { Response } \\
\text { time }\end{array}$ & Reference \\
\hline CPNTs & $\mathrm{nr}$ & $0.5-20 \mathrm{mM}$ & $\mathrm{nr}$ & $5-10 \mathrm{~s}$ & Yoon et al. (2008) \\
\hline Graphene & $0.4086 \mathrm{~mA} \mathrm{mM}^{-1}$ & $1.25-10 \mathrm{mM}$ & $1.25 \mathrm{mM}$ & $\mathrm{nr}$ & Cagang et al. (2016) \\
\hline Graphene & $2.5 \mu \mathrm{AmM}^{-1}$ & $0.1-10 \mathrm{mM}$ & $0.1 \mathrm{mM}$ & $\mathrm{nr}$ & You and Pak (2014) \\
\hline $\mathrm{rGO} / \mathrm{C}-\mathrm{PPy} \mathrm{NT}$ & $\mathrm{nr}$ & $\mathrm{nr}$ & $1 \mathrm{nM}$ & $<1 \mathrm{~s}$ & Park et al. (2015) \\
\hline CNTFs & $0.302 \mathrm{mV} \mathrm{mg}{ }^{-1} \mathrm{dl}^{-1}$ & $60-360 \mathrm{mg} \mathrm{dl}^{-1}$ & $60 \mathrm{mg} \mathrm{dL}^{-1}$ & $\mathrm{nr}$ & Tsai et al. (2013) \\
\hline ZnO NRs & $38.9 \mu \mathrm{A} \mathrm{mM}^{-1}$ & $800 \mathrm{nM}$ to $25 \mathrm{mM}$ & $800 \mathrm{nM}$ & $\mathrm{nr}$ & Lee and Chiu (2015) \\
\hline $\mathrm{ZnO}$ & $\mathrm{nr}$ & $1-100 \mu \mathrm{M}$ & $1 \mu \mathrm{M}$ & $<0.1 \mathrm{~s}$ & Ali et al. (2009) \\
\hline $\mathrm{ZnO}$ & $2.7 \mathrm{~A} \mathrm{mM}^{-1}$ & $10-30 \mathrm{mM}$ & $\mathrm{nr}$ & $20 \mathrm{~s}$ & Yano et al. (2012) \\
\hline MWCNTCOOH/PAN & $\mathrm{nr}$ & $0.005-50 \mathrm{mM}$ & $0.5 \mathrm{mM}$ & $10 \mathrm{~s}$ & Fathollahzadeh et al. (2016b) \\
\hline Bilayer $\mathrm{MoS}_{2}$ & $260.75 \mathrm{~mA} \mathrm{mM}^{-1}$ & $300 \mathrm{nM}$ to $30 \mathrm{mM}$ & $300 \mathrm{nM}$ & $<1 \mathrm{~s}$ & Our research \\
\hline
\end{tabular}

low concentration which from $0 \mathrm{nM}$ to $1 \mu \mathrm{M}$ was detected by the change of output characteristic curves, as shown in Fig. 5a.

The detection limit of our biosensor is $300 \mathrm{nM}$. The $I_{\mathrm{ds}}$ as a function of glucose concentration was shown in Fig. 5b. The sensitivity of the glucose biosensor can be calculated as high as $260.75 \mathrm{~mA} \mathrm{mM}^{-1}$. And the response time $(<1 \mathrm{~s})$ and the linear regions (300 $\mathrm{nM}$ to $30 \mathrm{mM}$ ) were tested in our experiments. Analytical features of some reported for glucose biosensors based on the FET are summarized in the Table 2 and compared with those parameters obtained from our results using bilayer $\mathrm{MoS}_{2}$ FET. As shown in Table 2, the proposed ZnO-based glucose biosensor shown higher sensitivity, ${ }^{28}$ shorter response time $^{45}$ and wider linear dynamic range ${ }^{50}$ than those previous reports. ${ }^{26,27,46,47,51-55}$ And the detection limit of the reduced graphene oxide/carboxylated polypyrrole nanotube (rGO/C-PPy NT) FET based biosensor ${ }^{42}$ was better than other glucose biosensors. ${ }^{26-28,45-47,50-55}$ Compared with previous researches, the bilayer $\mathrm{MoS}_{2}$-based FET we prepared show significant advantages in high sensitivity detection of extremely low concentration glucose solution.

\section{Conclusions}

In summary, a biosensor based on the bilayer $\mathrm{MoS}_{2}$ back-gate FET was fabricated and demonstrated for glucose detection successfully in our research. In particular, the glucose concentration was detected by the $\mathrm{MoS}_{2}$ FET for the first time. Considering the concentration of the fasting blood ranges from 3.9 to $6.1 \mathrm{mM}$, the concentration was detected in the range of $0-$ $30 \mathrm{mM}$ by the glucose biosensor we prepared. Through measurements of the $I_{\mathrm{ds}}$, the fabricated $\mathrm{MoS}_{2}$ FET biosensor shown a good sensing performance. The high sensitivity of $260.75 \mathrm{~mA} \mathrm{mM}{ }^{-1}$ was achieved for the detection of glucose solution which has the extremely low concentration level $(300$ $\mathrm{nM}$ ). The other advantages of our biosensor such as short response time ( $<1 \mathrm{~s})$, good stability, small size and trace detection were all demonstrated in our studies. This article open up a new path for the applications about the $\mathrm{MoS}_{2}$ FET. In practical sensing applications, we can design a bio-integrated circuit which contains a FET, an operational amplifier, a comparator and an LED to achieve the macroscopic, fast detection. That can be used to realize the miniaturization and real-time detection of human blood glucose concentration in the future.

\section{Conflicts of interest}

There are no conflicts to declare.

\section{Acknowledgements}

This work is supported by the "111" Project of China (D17017), the National Natural Science Foundation of China (21703017, 11674038, 61404009), the Advance Research Project of Weapon and Equipment (61404140201), the Project of Education Department of Jilin Province (JJKH20170611KJ), and the Developing Project of Science and Technology of Jilin Province (20160520117JH).

\section{References}

1 D. Lembke, S. Bertolazzi and A. Kis, Acc. Chem. Res., 2015, 48, 100-110.

2 D. Krasnozhon, D. Lembke, C. Nyffeler, Y. Leblebici and A. Kis, Nano Lett., 2014, 14, 5905-5911.

3 K. F. Mak, C. Lee, J. Hone, J. Shan and T. F. Heinz, Phys. Rev. Lett., 2010, 105, 136805.

4 W. X. Gu, J. Y. Shen and X. Y. Ma, Nanoscale Res. Lett., 2014, 9, 100.

5 T. Kawanago and S. Oda, Appl. Phys. Lett., 2016, 108, 041605. 6 Y. Chen, X. D. Wang, P. Wang, H. Huang, G. J. Wu, B. Tian, Z. C. Hong, Y. T. Wang, S. Sun, H. Sheng, J. L. Wang, W. D. Hu, J. L. Sun, X. J. Meng and J. H. Chu, ACS Appl. Mater. Interfaces, 2016, 8, 32083-32088. 
7 D. J. Late, B. Liu, H. S. S. R. Matte, V. P. Dravid and C. N. R. Rao, ACS Nano, 2012, 6, 5635-5641.

8 D. Jariwala, V. K. Sangwan, D. J. Late, J. E. Johns, V. P. Dravid, T. J. Marks, L. J. Lauhon and M. C. Hersam, Appl. Phys. Lett., 2013, 102, 173107.

9 P. K. Kannan, D. J. Late, H. Morgan and C. S. Rout, Nanoscale, 2015, 7, 13293-13312.

10 D. J. Late, P. A. Shaikh, R. Khare, R. V. Kashid, M. Chaudhary, M. A. More and S. B. Ogale, ACS Appl. Mater. Interfaces, 2014, 6, 15881-15888.

11 D. Sarkar, W. Liu, X. J. Xie, A. C. Anselmo, S. Mitragotri and K. Banerjee, ACS Nano, 2014, 4, 3992-4003.

12 W. Yang, K. R. Ratinac, S. P. Ringer, P. Thordarson, J. J. Gooding and F. Braet, Angew. Chem., Int. Ed., 2010, 49, 2114-2138.

13 M. S. Makowski and A. Ivanisevic, Small, 2011, 7(14), 18631875.

14 Y. Ohno, K. Maehashi, Y. Yamashiro and K. Matsumoto, Nano Lett., 2009, (9), 3318-3322.

15 Y. Ohno, K. Maehashi and K. Matsumoto, J. Am. Chem. Soc., 2010, 132, 18012-18013.

16 M. Dankerl, M. V. Hauf, A. Lippert, L. H. Hess, S. Birner, I. D. Sharp, A. Mahmood, P. Mallet, J. Y. Veuillen, M. Stutzmann and J. A. Garrido, Adv. Funct. Mater., 2010, 20, 3117-3124.

17 D. J. Late, Y. K. Huang, B. Liu, J. Acharya, S. N. Shirodkar, J. J. Luo, A. Yan, D. Charles, U. V. Waghmare, V. P. Dravid and C. N. R. Rao, ACS Nano, 2013, 7, 4879-4891.

18 G. Yoo, H. Park, M. Kim, W. G. Song, S. Jeong, M. H. Kim, H. Lee, S. W. Lee, Y. K. Hong, M. G. Lee, S. Lee and S. Kim, Nano Res., 2017, 10(3), 767-775.

19 B. Liu, L. Chen, G. Liu, A. N. Abbas, M. Fathi and C. Zhou, ACS Nano, 2014, 8, 5304-5314.

20 J. W. Huang, Y. Q. He, J. Jin, Y. R. Li, Z. P. Dong and R. Li, Electrochim. Acta, 2014, 136, 41-46.

21 J. W. Huang, Z. P. Dong, Y. D. Li, J. Li, J. Wang, H. D. Yang, S. W. Li, S. J. Guo, J. Jin and R. Li, Sens. Actuators, B, 2013, 182, 618-624.

22 X. Y. Li and X. Z. Du, Sens. Actuators, B, 2017, 239, 536-543.

23 L. M. Lu, H. B. Li, F. L. Qu, X. B. Zhang, G. L. Shen and R. Q. Yu, Biosens. Bioelectron., 2011, 26, 3500-3504.

24 K. I. Ozoemena and T. Nyokong, Electrochim. Acta, 2006, 51, 5131-5136.

25 Y. Y. Su, B. B. Luo and J. Z. Zhang, Anal. Chem., 2016, 88, 1617-1624.

26 Y. H. Kwak, D. S. Choi, Y. N. Kim, H. Kim, D. H. Yoon, S. S. Ahn, J. W. Yang, W. S. Yang and S. Seo, Biosens. Bioelectron., 2012, 37, 82-87.

27 H. Yoon, S. Ko and J. Jang, J. Phys. Chem. B, 2008, 112, 99929997.

28 M. Yano, K. Koike, K. Ogata, T. Nogami, S. Tanabe and S. Sasa, Phys. Status Solidi, 2012, 9, 1570-1573.

29 Y. M. Lin, K. A. Jenkins, A. Valdes-Garcia, J. P. Small, D. B. Farmer and P. Avouris, Nano Lett., 2008, 9, 422-426.
30 P. Wei, N. Liu, H. R. Lee, E. Adijanto, L. Ci, B. D. Nabb, J. Q. Zhong, J. Park, W. Chen, Y. Cui and Z. Bao, Nano Lett., 2013, 13, 1890-1897.

31 Y. M. Lin, C. Dimitrakopoulos, K. A. Jenkins, D. B. Farmer, H. Y. Chiu, A. Grill and P. Avouris, Science, 2010, 327, 662.

32 S. Lebegue and O. Eriksson, Phys. Rev. B: Condens. Matter Mater. Phys., 2009, 79, 115409.

33 A. Splendiani, L. Sun, Y. Zhang and F. Wang, Nano Lett., 2010, 10, 1271.

34 A. Kuc, N. Zibouche and T. Heine, Phys. Rev. B: Condens. Matter Mater. Phys., 2011, 83, 245213.

35 S. L. Li, K. Komatsu, S. Nakaharai, Y. F. Lin, M. Yamamoto, X. F. Duan and K. Tsukagonshi, ACS Nano, 2014, 1283612842.

36 S. Kim, A. Konar, W. S. Hwang, J. H. Lee, J. Lee, J. Yang, C. Jung, H. Kim, J. Yoo, J. Y. Choi, Y. W. Jin, S. Y. Lee, D. Jena, W. Choi and K. Kim, Nat. Commun., 2012, 20, 1038.

37 B. W. H. Baugher, H. O. H. Churchill, Y. Yang and P. J. Herrero, Nano Lett., 2013, 13, 4212-4216.

38 H. Li, Z. Y. Yin, Q. Y. He, H. Li, X. Huang, G. Lu, D. W. H. Fam, A. L. Y. Tok, Q. Zhang and H. Zhang, Small, 2012, 8, 63-67.

39 A. S. Pawbake, M. S. Pawar, S. R. Jadkar and D. J. Late, Nanoscale, 2016, 8, 3008-3018.

40 M. X. Ye, D. Winslow, D. Y. Zhang, R. Pandey and Y. K. Yap, Photonics, 2015, 2, 288-307.

41 S. Tongay, W. Fan, J. Kang, J. Park, U. Koldemir, J. Suh, D. S. Narang, K. Liu, J. Ji, J. Li, R. Sinclair and J. Wu, Nano Lett., 2014, 14, 3185.

42 X. Li, J. H. Li, X. H. Wang, J. X. Hu, X. Fang, X. Y. Chu, Z. P. Wei and J. J. Shan, Integr. Ferroelectr., 2014, 158, 26-42.

43 C. G. Lee, H. G. Yan, L. E. Brus, T. F. Heinz, J. Hone and S. Ryu, ACS Nano, 2010, 5, 2695-2700.

44 M. Fathollahzadeh, M. Hosseini, B. Haghighi and M. Fathipour, Anal. Chim. Acta, 2016, 924, 99-105.

45 R. Ahmad, N. Tripathy and Y. B. Hahn, Biosens. Bioelectron., 2013, 45, 281-286.

46 M. Zhang, C. Z. Liao, C. H. Mak, P. You, C. L. Mak and F. Yan, Sci. Rep., 2015, 5, 8311.

47 W. L. Tsai, Y. S. Chien, P. Y. Yang, I. C. Lee, K. Y. Wang and H. C. Cheng, Sens. Actuators, A, 2013, 204, 31-36.

48 Y. H. Lin, C. P. Chu, C. F. Lin, H. H. Liao, H. H. Tsai and Y. Z. Juang, Biomed. Microdevices, 2015, 17, 111.

49 X. You and J. J. Pak, Sens. Actuators, B, 2014, 202, 1357-1365. 50 S. M. U. Ali, O. Nur, M. Willander and B. Danielsson, IIEEE Trans. Nanotechnol., 2009, 6, 678-683.

51 A. A. Cagang, I. H. Abidi, A. Tyagi, J. Hu, F. Xu, T. J. Lu and Z. Luo, Anal. Chim. Acta, 2016, 917, 101-106.

52 X. Q. You and J. J. Pak, Sens. Actuators, B, 2014, 202, 13571365.

53 J. W. Park, C. Lee and J. Jang, Sens. Actuators, B, 2015, 208, 532-537.

54 C. T. Lee and Y. S. Chiu, Sens. Actuators, B, 2015, 210, 756-761. 55 M. Fathollahzadeh, M. Hosseini, B. Haghighi, M. Kolahdouz and M. Fathipour, Anal. Chim. Acta, 2016, 924, 99-105. 